Published in final edited form as:

J Cardiovasc Electrophysiol. 2008 August ; 19(8): 878. doi:10.1111/j.1540-8167.2007.01075.x.

\title{
Placebo CRT
}

\author{
Niraj Varma, MD, FRCP ${ }^{*}$, , Ping Jia, PhD*, and Yoram Rudy, PhD ${ }^{\ddagger}$ \\ "Cardiac Bioelectricity Research and Training Center, Case Western Reserve University, \\ Cleveland, Ohio \\ tUniversity Hospitals of Cleveland, Cleveland, Ohio \\ ¥Cardiac Bioelectricity and Arrhythmia Center, Washington University in St. Louis, St. Louis, \\ Missouri
}

\section{Case}

Cardiac resynchronization therapy (CRT) improves survival by paced pre-excitation of the lateral /posterolateral LV1. This patient with a history of anterior and anterolateral wall LV infarction (LV ejection fraction 10\%, end- diastolic internal diameter $8.2 \mathrm{~cm}$ ) improved two functional classes (NYHA IV to II) within 4 weeks of CRT. However, electrocardiographic imaging (ECGI) of ventricular electrical activation was at variance with this clinical effect (See figure). ECGI is a noninvasive modality for imaging epicardial potentials, electrograms, isochrones (activation sequences) and repolarization patterns from body surface electrocardiographic measurements2. Echocardiography in susbsequent months demonstrated progressive deterioration, with LV dilatation and diminishing ejection fraction. The patient deceased from heart failure shortly thereafter. Thus, this ECGI study had revealed lack of intended electrical effect of LV pacing, presaging CRT failure, despite symptomatic improvement. Non-invasive electrical imaging may have significant future utility for rapid assessment of pacing therapies.

\section{Acknowledgments}

In addition to the authors, Charulatha Ramanathan, PhD, Raja N. Ghanem PhD and Kyungmoo Ryu, PhD, also participated in the ECGI study.

The study was supported by NIH-NHLBI Merit Award R37-HL-033343 and Grant RO1- HL-49054 to Dr. Rudy.

\section{References}

1. Cleland JG, Daubert JC, Erdmann E, Freemantle N, Gras D, Kappenberger L, Tavazzi L. The effect of cardiac resynchronization on morbidity and mortality in heart failure. N Engl J Med. 2005; 352:1539-49. [PubMed: 15753115]

2. Ramanathan C, Ghanem RN, Jia P, Ryu K, Rudy Y. Noninvasive electrocardiographic imaging for cardiac electrophysiology and arrhythmia. Nat Med. 2004; 10:422-428. [PubMed: 15034569]

\footnotetext{
Address for Correspondence: Niraj Varma MD, FRCP, Director Cardiac Electrophysiology Laboratory, Loyola University Medical Center, 2160 South First Avenue, Maywood, Illinois 60153. Tel (708) 216 2653; Fax (708) 216 6829; nivarma@lumc.edu.

Dr. Rudy chairs the scientific advisory board and holds equity in CardioInsight Technologies. He is an inventor of ECGI technology, for which Case Western Reserve University and Washington University hold patents.

Dr. Jia is an inventor of ECGI technology and is an equity holder and a paid employee of CardioInsight Technologies.

Dr. Varma is an investigator for CardioInsight Technologies.
} 


\section{Isochrones during Biventricular Pacing}

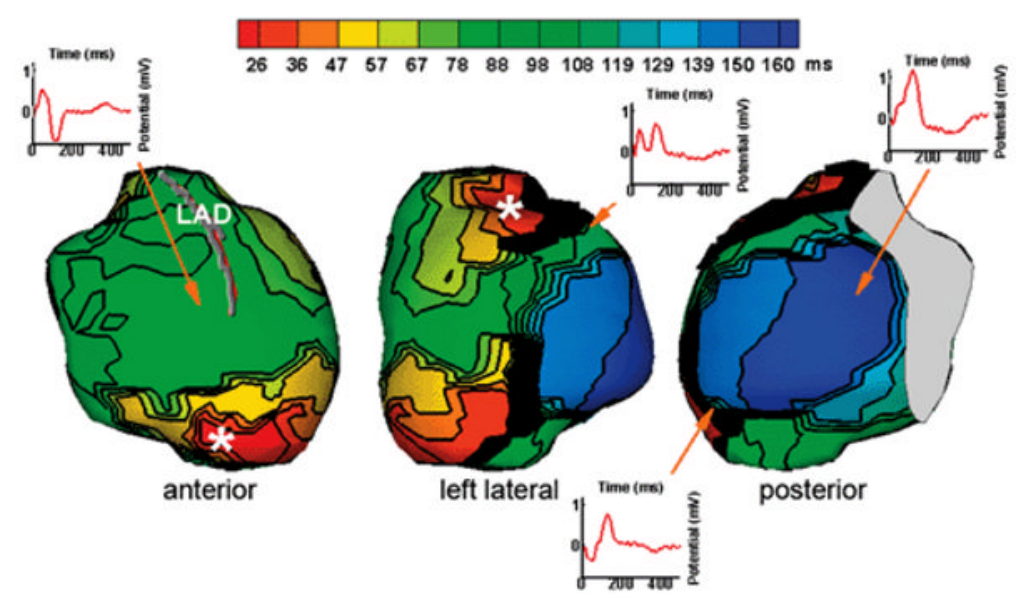

Figure.

The figure depicts an ECGI-constructed epicardial isochrone map during simultaneous biventricular pacing (CRT). Epicardial surfaces of both ventricles are displayed in three views: anterior, left lateral, and posterior. There is overlap between adjacent views. The left anterior descending (LAD) coronary artery is marked. Selected ECGI-reconstructed epicardial electrograms are indicated by arrows. Pacing sites (RV and LV, asterisks), as expected, are the earliest ventricular sites to be activated (red). Thereafter, LV activation is irregular with development of regions of conduction block (thick black markings) and slowing (crowded isochrones) displaying fractionated local electrograms. These delay activation of a large territory of the lateral/posterolateral LV. In fact, this region is activated terminally (blue) despite pacing from an immediately adjacent site. Electrograms are preserved in this area indicating epicardial viability. Hence, LV pacing failed to achieve target area preexcitation. 